\title{
The Contribution of Product Oversight and Governance (POG) to the Single Market: A Set of Organisational Rules for Business Conduct
}

\author{
Pierpaolo Marano
}

\section{Introduction}

Product oversight and governance (POG) is one of the major innovations, if not the most significant, introduced by the Insurance Distribution Directive (IDD). It is somewhat unusual, however, that this novelty is not reflected both in the proposal for amending the Insurance Mediation Directive, which would later become the IDD and in the preliminary work carried out by the Commission for the drafting of that proposal. POG appeared in the IDD as a mere "copy and paste" from the Market in Financial Instruments Directive II (MiFID II). The initial draft of the MiFID II also did not contain any rules on POG. Thus, the entry of POG into European Union (EU) law was not accompanied by in-depth analyses of the EU bodies that decided to adopt that set of rules in the financial and insurance field. ${ }^{1}$ Such a genesis of POG delivers a set of rules that should be investigated to understand the effects and usefulness.

POG is consistent, in principle, with the evolution in the EU approach to insurance regulation. Solvency II identified the protection of policyholders and beneficiaries as the main objective of supervision. ${ }^{2}$ A prospective and risk-based approach is the basis of supervision that includes the verification on a continuous basis of the proper operation of the insurance or reinsurance business and of the

\footnotetext{
${ }^{1}$ However, see the Opinion issued by ESMA, Structured retail products - Good practices for product governance arrangements, March 2014, available at https://www.esma.europa.eu/sites/ default/files/library/2015/11/2014-332_esma_opinion_u_structured_retail_products_-_good_prac tices_for_product_governance_arrangements.pdf.

${ }^{2}$ See Article 27 of Solvency II.

P. Marano $(\bowtie)$

Catholic University of the Sacred Heart, Department of Legal Sciences, Milan, Italy

e-mail: pierpaolo.marano@unicatt.it

P. Marano, K. Noussia (eds.), Insurance Distribution Directive, AIDA Europe

Research Series on Insurance Law and Regulation 3,

https://doi.org/10.1007/978-3-030-52738-9_3
} 
compliance with supervisory provisions by insurance and reinsurance undertakings. ${ }^{3}$ The IDD extended the set of rules on the proper operation of the insurance (and reinsurance) business and POG is a crucial component of this political choice. The set of rules on POG are addressed not only to insurance undertakings and distributors but also to the supervisory authorities. POG aims at anticipating customer protection at the design stage for product marketing, and it enables supervisory authorities to have a clearer picture of the businesses processes that are behind the products marketed to customers.

This chapter aims to investigate how POG fits into the overall EU insurance regulation. Thus, the first paragraph will analyse the origin of POG concept that can be attributed to the United Kingdom (UK). This "historical" research on the rules and underlying principles appears necessary given the absence of preliminary studies on POG at EU level before its introduction into the IDD. The second paragraph illustrates how IDD incorporated the POG devolving the adoption of the detailed rules to the Commission. The third and fourth paragraphs evaluate, respectively, the current and potential role that the new rules can play in building an authentic Single Market in the insurance sector.

\section{The Origin of POG as a Regulatory Response Based on Principles of Businesses}

The concept of POG was mainly developed in the $\mathrm{UK},{ }^{4}$ as one of the regulatory responses to the failings in the UK regulatory framework on financial services, which emerged with the financial crisis. ${ }^{5}$ The UK regulatory framework was based on the assumption that adequate consumer protection would be achieved provided sales processes were fair, and product feature disclosure was transparent. The UK authorities developed POG to complement such regulatory framework rather than replacing. They decided to require: $(i)$ providers to demonstrate the value for

\footnotetext{
${ }^{3}$ See article 29(1) of Solvency II.

${ }^{4}$ Some inspiration can be found in the Resolution n. 9019104 of 2 March 2009 on illiquid investment products, which was issued by the Italian authority responsible for regulating the Italian financial market (CONSOB). The principle of "acting honestly, fairly and professionally in accordance with the best interest of customers" (see Article 19.1 MiFID) was interpreted in the sense of requiring issuers of illiquid investment products to design their commercial policy evaluating the compatibility of each product with the characteristics and needs of the customers to whom they are offered. Thus CONSOB requires the definition of business processes to allow, even in abstracts terms, the assessment of the financial needs of the selected target market compared to those satisfied by the products which should be offered to them, in the concrete selection phase of the products to be distributed and, more importantly, in the possible engineering phase. In addition, the activities above shall be approved by the administrative body and verified by the compliance function. See also Autorité des Marchés Financiers (AMF), La commercialisation des instruments financiers complexes, Position No 2010 - 05, of 15 October 2010.
}

${ }^{5}$ See Marano (2019), pp. $60 \mathrm{ff}$. 
the customer of the products they are designing, and (ii) providers and distributors to take care of their customers. The new set of rules was based around the idea that a more structured design and marketing process, involving the board of directors and where company functions are always attentive to meeting customer needs and interests, should prevent the customer bias without the intervention of supervisory authorities. POG should allow supervised entities to be more aware of the embedded "value for customers" in their products, while supervisors can take rapid action to stop problems from growing and affecting large numbers of consumers, and to deter the creation of products likely to lead to consumer detriment. ${ }^{6}$

The UK authorities considered that POG was already embedded in principles on business conduct, but the regulatory intervention was deemed necessary to detail POG. This new supervisory approach has been completed turning some of the Financial Service Authority (FSA) ${ }^{7}$ previously published material on treating customers fairly and the responsibilities of product providers and distributors into rules. ${ }^{8}$ FSA Handbook related to "The Responsibilities of Providers and Distributors for the Fair Treatment of Customers" provided guidance for POG, which were inferred from some Principles of Businesses. Thus, principles operating prior to the financial crisis were deemed fit to found the new regulatory approach. These "evergreen" principles needed to be more detailed and, therefore, business conduct switched from a principle-based regulation to a detailed-based regulation. ${ }^{9}$

POG was built around four principles of businesses. The following can be considered like the principle that oversees all new regulatory architecture: A firm must conduct its business with due skill, care and diligence. ${ }^{10}$ This principle permeates both the organisational structure of the firm and its approach to the customer, while the other three principles appear to be the application or specification of this general rule. One of them is more focused on organisational: A firm must take reasonable care to organise and control its affairs responsibly and effectively, with adequate risk management systems. ${ }^{11}$ Another principle refers to the quality of the product/service offered to the customer: A firm must pay due regard to the interests of its customers and treat them fairly. ${ }^{12}$ The other principle concerns the information flow with the customer: A firm must pay due regard to the information needs of its

\footnotetext{
${ }^{6}$ FSA, Discussion Paper on Product Intervention, January 2011, p. 16.

${ }^{7}$ The Financial Conduct Authority (FCA) replaced the Financial Services Authority (FSA) since 1 April 2013.

${ }^{8}$ See: FSA, Treating Customers Fairly. Towards Fair Outcomes for Consumers, July 2006; FSA, Treating Customers Fairly. Structured Investment Products, October 2009; FSA, Finalised Guidance - Retail Product Development and Governance, March 2012; FCA, Structured Products: Thematic Review of Product Development and Governance, March 2015; HM Treasury, A New Approach to Financial Regulation: Judgement, Focus and Stability, 2012. An analysis of the FSA Treating Customers Fairly Initiative is provided by Georgosouli (2011), pp. 405 ff.

${ }^{9}$ In a broader perspective, see Marcacci (2017), pp. $305 \mathrm{ff}$.

${ }^{10}$ See Principle of Business No. 2.

${ }^{11}$ See Principle of Business No. 3.

${ }^{12}$ See Principle of Business No. 6.
} 
clients and communicate information to them in a way which is clear, fair and not misleading. ${ }^{13}$

The transition from a principle-based regulation to a detailed-based regulation leads as an obvious deduction that the rules have increased in number and detail. However, this finding is reductive compared to the real innovation that this transition entails: these rules become an integral part of the organisation of insurance undertakings and their distributors. At the same time, supervision must ensure that the organisation of these entities also complies with these rules.

Regarding providers, ${ }^{14}$ the general principle together with the organisational principle and the principle of product/service quality, allow the UK authorities to affirm the following detailed rules that form the basis of POG. Providers shall identify the target market, namely which types of customer the product or service is likely to be suitable (or not suitable) for. Thus, the provider shall (i) stress-test the product or service to identify how it might perform in a range of market environments and how the customer could be affected, and (ii) have in place systems and controls to manage adequately the risks posed by-product or service design.

Moreover, the general principle under which a firm must conduct its business with due skill, care and diligence affects the information provided to distributors from providers. Such principle "implies" that providers shall (i) make clear if that information is not intended for customer use; and (ii) ensure the information is sufficient, appropriate and comprehensible in substance and form, including considering whether it will enable distributors to understand it enough to give suitable advice (where advice is given) and to extract any relevant information and communicate it to the end customer. As part of meeting this standard, the provider may wish to consider, about each distribution channel or type of distributor, what information distributors of that type already have, their likely level of knowledge and understanding, their information needs and what form or medium would best meet those needs (which could include discussions, written material or training as appropriate).

This principle is relevant when selecting a distribution channel, and it is complemented with those concerning the quality of the product/service offered to the customer, and the flow of information with the customer. In particular, a provider shall: $(i)$ decide whether this is a product where customers would be wise to seek advice; (ii) review how what is occurring in practice corresponds to (or deviates from) what was initially planned or envisaged for the distribution of its products or services given the target market. This activity involves collecting and analysing appropriate management information such that the firm can detect patterns in

\footnotetext{
${ }^{13}$ See Principle of Business No. 7.

${ }^{14}$ FSA Handbook related to "The Responsibilities of Providers and Distributors for the Fair Treatment of Customers", which is availbale at https://www.handbook.fca.org.uk/handbook/docu ment/rppd/RPPD_Full_20180103.pdf, specifies the term "provider" include persons who offer services such as portfolio management (through distributors or otherwise) as well as those who develop, manage or package products such as life insurance, general insurance or investment products or who develop or enter into home finance transactions (i.e. mortgages, home reversion plans and home purchase plans).
} 
distribution as compared with the planned target market, and can assess the performance of the distribution channels through which its products or services are being distributed; (iii) act when it has concerns, for example by ceasing to use a particular distribution channel.

The above principles detailing the general one also incorporate the rules that are inferred for the information to customers. They request a provider to: (i) pay regard to its target market, including its likely level of financial capability; (ii) take account of what information the customer needs to understand the product or service, its purpose and the risks, and communicate information in a way that is clear, fair and not misleading; (iii) have in place systems and controls to manage effectively the risks posed by providing information to customers.

Those principles are also relevant, finally, for establishing detailed rules in the area of post-sale responsibility. Thus, a provider $(i)$ in supplying information direct to the customer, must ensure that the information is communicated in a way which is clear, fair and not misleading; (ii) should periodically review products whose performance may vary materially to check whether the product is continuing to meet the general needs of the target market that it was designed for, or whether the product's performance will be significantly different from what the provider originally expected and communicated to the distributor or customer at the time of the sale. If this occurs, the provider should consider what action to take, such as whether and how to inform the customer of this (to the extent the customer could not reasonably have been aware) and of their option to seek advice, and whether to cease selling the product; (iii) should communicate to the customer contractual 'breakpoints' such as the end of a long tie-in period that may have a material impact on a customer that the customer cannot reasonably be expected to recall or know about already; (iv) should act fairly and promptly when handling claims or when paying out on a product that has been surrendered or reached maturity. In doing this, the provider should meet any reasonable customer expectations that it may have created about the outcomes or how the process would be handled; $(v)$ must establish, implement and maintain effective and transparent customer complaint-handling systems.

The principles examined so far are also relevant for distributors. Regarding distributor responsibilities, the general principle as detailed by others, allows inferring several detailed rules in the area of financial promotions. Hence, distributors $(i)$ shall have in place systems and controls to manage effectively the risks posed by financial promotions; and (ii) in passing on a promotion created by a provider, must act with due skill, care and diligence. A firm will not contravene the financial promotions rules where it communicates a promotion produced by another person provided the firm takes reasonable care to establish that another firm has confirmed compliance with the relevant detailed rules, amongst other matters.

Moreover, the general principle as detailed with those concerning the quality of the product/service offered to the customer, and the flow of information with the customer led to set up the following rules when providing information to a customer before or at the point of sale. Thus, providers: $(i)$ shall consider, when passing provider materials to customers, whether it understands the information provided; 
(ii) shall ask the provider to supply additional information or training where that seems necessary to understand the product or service adequately; (iii) shall not distribute the product or service if it does not understand it sufficiently, especially if it intends to provide advice; and (iv) when providing information to another distributor in a distribution chain, should consider how the further distributor will use the information, such as whether it will be given to customers. Firms should consider what information the further distributor requires and the reasonable level of knowledge and understanding of the further distributor and what medium may suit it best for the transmission of information.

The general principle as detailed with that related to the quality of the product/ service offered to the customer is relevant when advising on the selection of a provider. Thus, distributors shall consider: $(i)$ the nature of the products or services offered by the provider and how they fit with the customer's needs and risk appetite; and (ii) what impact the selection of a given provider could have on the customer in terms of charges or the financial strength of the provider, or possibly, where information is available to the distributor, how efficiently and reliably the provider will deal with the distributor or customer at the point of sale (or subsequently, such as when queries/complaints arise, claims are made, or a product reaches maturity).

The principles on organisational and the quality of the product/service offered to the customer allow to infer several rules in the area of post-sale responsibility. Hence, distributors: $(i)$ shall comply with any contractual obligation it has to the customer, for example, to provide ongoing advice or periodic reviews. In connection with this, distributors should also consider their responsibility to maintain adequate systems and controls to deliver on such reviews; (ii) shall consider any implied or express representation they made (during meetings, correspondence or promotional material, for example) and, in particular, where a customer has reasonable expectations based on the prior statements of a distributor, the distributor should meet these expectations; (iii) where involved in handling claims or paying out on a product that has been surrendered or reached maturity, should meet any reasonable expectations that the distributor has created in the customer's mind about how the process would be handled; (iv) must establish, implement and maintain effective and transparent customer complaint-handling systems; and $(v)$ shall pass any communications received from customers (intended for or suited to providers to act upon) to providers in a timely and accurate way.

In conclusion, the UK hands over the EU a set of organisational rules inferred from business conduct principles. POG embeds the customer's protection in the organisational rules applying to providers and distributors. Thus, firms are called to comply with internal procedures aiming at creating products that have a real value for the customers to whom they will be offered, and not just a value for the shareholders, directors and senior management of the undertaking. Moreover, POG aims at anticipating customer protection at the design stage for product marketing because it enables supervisory authorities to have a clearer picture of the businesses processes that are behind the products marketed to customers. The early knowledge of the design process should facilitate the supervisory authorities to exercise their intervention powers in order to prevent or reduce detriments arising 
from products that are not developed in the best interest of the customers. ${ }^{15}$ To this purpose, authorities need to be properly equipped with skilled staff in order to quickly understand the design of the products, ${ }^{16}$ if the intervention powers to be exercised promptly. ${ }^{17}$

\section{The Transposition of POG in the EU Law: Organizational Rules for the Business Conduct}

The EU fully embraced the set of rules on POG and their rationale as elaborated by the UK. POG was not included in the initial draft proposal of the IDD, which was issued by the European Commission in July 2012, and the introduction of POG for the insurance industry was not preceded by specific activity of the European Commission, even in terms of cost/benefit analysis. Notwithstanding this, the European Supervision Authorities (ESAs) adopted a Joint position on manufacturers' products oversight and governance processes in 2013, where the legal basis of EIOPA's involvement was founded $(i)$ in the possibility that product governance provisions may be included in the Directive on insurance mediation (IMD) or any future legislative act replacing IMD and (ii) as part of the principle set forth by Recital 16 of the Directive Solvency II under which the main objective of insurance and reinsurance regulation and supervision is the "adequate protection of policyholders and beneficiaries". ${ }^{18}$ This, because such a principle is supplemented by additional requirements in Articles 41(1) and 41(6) of Solvency II, which include having effective systems of internal control and governance to provide for sound and prudent management of the business. ${ }^{19}$ IDD outlines the characteristic features of POG. They are supplemented by Commission Delegated Regulation (EU) 2017/ 2358 of 21 September 2017, which is based on the Technical advice provided by the EIOPA in February 2017. ${ }^{20}$

\footnotetext{
${ }^{15}$ Ferran (2012), pp. 264 ff. See also: Tomic (2018), pp. 229-255; Busch (2017), pp. 409-420; Colaert (2019), pp. 395-402.

${ }^{16}$ Brandt (2011), p. 8 noted "This is not to say that current supervisory staff are inadequate; however, it appears that what the FSA is proposing is a radical and challenging benchmark which requires a significant investment in resourcing levels, training and overall staff quality".

${ }^{17}$ About the genesis of product intervention, see Moloney (2012), pp. $186 \mathrm{ff}$.

${ }^{18}$ See also Van Hulle (2019), p. 10.

${ }^{19}$ See Joint Position of the European Supervisory Authorities on Manufacturers' Product Oversight \& Governance Processes, at point 22. The Joint position is available at https://www.eba.europa.eu/ documents/10180/15736/JC-2013-77+\%28POG+-+Joint+Position\%29.pdf.

${ }^{20}$ The Final report is available at https://eiopa.europa.eu/Publications/Reports/EIOPA\%20Final_ Report_on_IDD_Technical\%20Advice.pdf. See also EIOPA, Preparatory Guidelines on product oversight and governance arrangements by insurance undertakings and insurance distributors, March 2016.
} 
The interpretative questions arising from the formulation of the rules on POG are not analysed in this essay. ${ }^{21}$ Here, the aim is to highlight the organisational nature of the new rules, that is, their characteristic of requiring manufacturers and distributors to adopt procedures and organisational structures through which carry out the process of design and distribution of products, ${ }^{22}$ and the supervisory authorities to adopt a risk-based and forward-looking approach when monitoring the compliance with POG.

POG rules as detailed in the Commission Delegated Regulation (EU) 2017/2358 call manufacturers for a 'product approval process' covering the maintenance, operation and review of product oversight and governance arrangements for insurance products and for significant adaptations to existing insurance products before those products are brought to the market or distributed to customers, as well as rules for product distribution arrangements for those insurance products. The product approval process shall contain measures and procedures for designing, monitoring, reviewing and distributing insurance products, as well as for corrective action for insurance products that are detrimental to customers. ${ }^{23}$ The product approval process shall be set out in a written policy ("product oversight and governance policy"), which shall be made available to the relevant staff. Manufacturers shall regularly review their product approval process to ensure that the process is still valid and up to date, and they shall amend the product approval process where necessary. ${ }^{24}$ The relevant actions, which are taken by manufacturers about their product approval process, shall be duly documented, kept for audit purposes and made available to the competent authorities upon request. ${ }^{25}$

Product oversight and governance policy adds to policies already prescribed by Solvency II. Such a policy requires to be implemented in the organisation of the manufacture. Thus, the policy must be implemented by the operating units dealing with the design and distribution of products, and monitored by the internal control system. This policy will enable competent authorities to supervise and assess whether the regulated entities comply with the regulatory requirements on POG, thus promoting customer's protection in the end. ${ }^{26}$ This is to say that such a policy is part of the system of governance of insurance undertakings that provides for sound and prudent management of their business. Thus, the written policy shall be the subject to prior approval by the administrative, management or supervisory body of

\footnotetext{
${ }^{21}$ A detailed analysis is provided by Marano (2019), p. $69 \mathrm{ff}$.

${ }^{22}$ In a broader perspective, this approach is qualified as "meta regulation" by Gunningham (2012), p. $135 \mathrm{ff}$. (Gunningham), p. $146 \mathrm{ff}$. (Coglianese et al), since legally force intermediaries to embrace specific management and control procedures, adopting a body of conduct of business rules approved under prudential supervision rationale.

${ }^{23}$ See Article 4 of Commission Delegated Regulation (EU) 2017/2358.

${ }^{24}$ See Article 4 of Commission Delegated Regulation (EU) 2017/2358.

${ }^{25}$ See Article 9 of Commission Delegated Regulation (EU) 2017/2358.

${ }^{26}$ See EIOPA, Final Report on Consultation Paper n. 16/006 on Technical Advice on possible delegated acts concerning the Insurance Distribution Directive, February 2017, p. 34.
} 
the manufacturer or equivalent structure (in the case of two-tier systems) ${ }^{27}$ as well as any material changes. ${ }^{28}$ Moreover, the administrative, management or supervisory body of the manufacturer or equivalent structure: $(i)$ is ultimately responsible for the establishment, subsequent reviews and continued compliance of the POG arrangements; and (ii) ensures that the POG arrangements are appropriately designed and implemented into the governing structures of the manufacturer. ${ }^{29}$

POG should include all decision-making processes (designing and developing) related to products that will be marketed or distributed to customers. ${ }^{30}$ In the case of insurance undertaking playing a "passive" role or a non-exclusive role in the decision-making process, a distinction should be made whether the insurance undertaking has $(i)$ contributed to the design of the product with another entity, or (ii) outsourced the design activities.

In the case sub $(i)$, an insurance undertaking and an insurance intermediary are both manufacturers of the same product if the conditions listed in the Commission Delegated Regulation are met. ${ }^{31}$ They are qualified as co-manufacturers, and they shall sign a written agreement that specifies their collaboration to comply with the requirements for manufacturers as referred to IDD, ${ }^{32}$ the procedures through which they shall agree on the identification of the target market and their respective roles in the product approval process.

In the case sub (ii), manufacturers designate a third party to design products on their behalf and remain fully responsible for compliance with the product approval process. ${ }^{33}$ The outsourcing to an entity other than an insurance intermediary falls outside the scope of the co-manufacturers rule. IDD prevents this entity from being regarded as a manufacturer. ${ }^{34}$ Thus, insurance undertaking will be solely responsible for the outsourced activity, ${ }^{35}$ and compliance with the product approval process. This clarification is relevant for insurance-based investment products because Regulation (EU) No 1286/2014 on Packaged Retail and Insurance-based Investment Product (PRIIP) provides a definition of PRIIPs manufacturer, which shall draw up for that product a key information document (KID) according to the requirements of that Regulation and shall publish the document on its website. Thus, if an insurance undertaking designates a third party (a PRIIP manufacturer) to design insurance products, the latter can be an entity falling outside the scope of POG, when such an entity is not an insurance intermediary. In this case, the insurance undertaking shall be the one entity to have to comply with POG rules because of the outsourcing of the

\footnotetext{
${ }^{27}$ See Article 41(3)(2) of Solvency II.

${ }^{28}$ See EIOPA, Final Report on Consultation Paper n. 16/006, cit., p. 35.

${ }^{29}$ See EIOPA, Final Report, cit., p. 35.

${ }^{30}$ Marano (2019), p. 69.

${ }^{31}$ See Article 2 of Commission Delegated Regulation (EU) 2017/2358.

${ }^{32}$ See Article 25(1) of IDD.

${ }^{33}$ See Article 4(5) of Commission Delegated Regulation (EU) 2017/2358.

${ }^{34}$ See Article 25(1) of IDD.

${ }^{35}$ See Article 49(1) of Solvency II.
} 
manufacturer of an insurance-based investment product to an entity that cannot be considered as co-manufacturer.

In both cases, sub $(i)$ and (ii), the activities required by the set of rules on POG are regarded as inherent in the organisation of the undertaking. They can be outsourced as other activities falling within the insurance production cycle or manufactured together by sharing their organisation between different entities.

Finally, the rules on POG also impact on the organisation of insurance intermediaries. If insurance intermediaries are co-manufacturers, the written agreement with the insurance undertaking/co-manufacturer has to specify the activities distributed between the two co-manufacturers within those listed in the set of rules on POG. Moreover, manufacturers have duties of properly selecting, informing and monitoring distribution channels. In contrast, distributors have to cooperate with manufacturers in monitoring the distribution of the insurance products to the identified target market, and they can set up or apply a specific distribution strategy. The co-operation between manufacturers and distributors has to be formalised in the product distribution arrangements. ${ }^{36}$ These agreements will regulate the flow of information between the entities involved and coordinate the respective organisations. They should allow (i) distributors to transmit information that is eligible to support product monitoring and review carried out by manufacturers, (ii) manufacturers to accept what distributors report because they can verify the accuracy of the data communicated by distributors. $^{37}$

\section{POG and the Single Market in Insurance: The Current Effects}

The previous paragraphs have highlighted that the set of rules on POG has been deduced from principles of conduct, and they become an essential part of the organisation of manufacturers and distributors. The transition from a principlebased regulation to a detailed-based regulation means that market's operators including supervisory authorities have to be organised to carry out their activities having in mind that products must include a real value for the customers ("target market"). POG seems capable of having multiple effects on the harmonisation process of insurance rules in the EU also contributing to their uniform interpretation, that is, to build up an effective Single Market. Some of these effects are obvious: POG is a tool for achieving better customer protection and coherent regulation for financial services across the UE. Other effects are less evident but no less criticial: POG extends the scope of harmonisation of organisational requirements and supports a convergent interpretation and application of the rules between supervisory authorities. This paragraph examines the effects that seem obvious, while the

\footnotetext{
${ }^{36}$ See Marano (2019), p. 84.

${ }^{37}$ See Marano (2019), p. 86.
} 
following one explores some effects that seem to derive from the set of rules on POG.

Regarding better customer protection, the protection of policyholders and beneficiaries is the main objective of supervision in the EU as already noted. The set of rules on POG meets this goal by aligning the approach to products with that on capital requirements. In both cases, the aim is to prevent the harmful event from occurring.

In particular, POG introduced a risk-based and prospective approach similar to that of Solvency II. The latter Directive requires insurance undertakings to have in place an effective system of governance which provides for sound and prudent management of the business, ${ }^{38}$ and an effective risk-management system to identify, measure, monitor, manage and report, on a continuous basis, the risks to which they are or could be exposed, and their interdependencies. ${ }^{39}$ Thus, a sound and prudent management of the business cannot disregard effective risk management, where the risk-management system has to cover the risks to be included in the calculation of the Solvency Capital Requirement as well as the risks which are not or not fully included in the calculation thereof. ${ }^{40}$ The risk assessment inherent in poorly designed products is part of the risk culture that insurance undertakings must introduce in their business processes and among the people who work for them. Undertakings have to supervise themselves, their processes, in order to prevent the design and distribution of products is detrimental to their customers. POG is a risk management tool that allows undertakings to prevent those risks by avoiding offering worthless products to customers. ${ }^{41}$

On the other hand, the supervision required by POG is similar to that arising from Solvency II. This latest Directive stated that supervision is based on a prospective and risk-based approach. ${ }^{42}$ This approach includes the verification on a continuous basis of the proper operation of the insurance business and of the compliance with supervisory provisions by insurance undertakings in order to minimise disruption or loss on the part of policyholders. ${ }^{43}$ POG is a tool that increases transparency to the supervisory authorities by improving their ability to understand and assess the process of manufacturing and distributing insurance products. POG discloses to the supervisory authority the persons/units involved in these processes, how the products are manufactured, and the purposes pursued with these products by the insurance undertakings. The advance knowledge of these processes is functional to

\footnotetext{
${ }^{38}$ See Article 41(1) of Solvency II.

${ }^{39}$ See Article 44(1) of Solvency II.

${ }^{40}$ See Article 44(2) of Solvency II.

${ }^{41}$ See EIOPA, Preparatory Guidelines on product oversight governance, cit., p. 4, which outlines that the organizational arrangements required under POG "have a substantial link to the system of governance under the Solvency II framework, requiring firms to have a sound and prudent management of the business under a risk based approach including an appropriate risk management system".

${ }^{42}$ See Van Hulle (2019), p. $372 \mathrm{f}$.

${ }^{43}$ Van Hulle (2019), p. 372.
} 
early intervention by the authorities if they realise how the products or processes are likely to be detrimental to customers. POG is, therefore, likely to affect the approach of the authorities supervising market conducts. Authorities are now required to prevent bias from arising to the customers rather than repressing the conduct leading to such bias.

IDD achieves customer protection also aligning the rules on insurance with some of those on financial products and services introduced with the MiFID I, in 2004, and MiFID II. In particular, it was previously found that IDD introduced POG as a substantial "copy and paste" from MiFID II. The same can be said about the general principle under which distributors must always act honestly, fairly and professionally in accordance with the best interest of their customers, and most of the additional rules on customer protection for insurance-based investment products aiming at levelling the playing field with financial products as required by Solvency II. This approach of the EU legislator has been called as "Mifidization" of the EU regulatory framework on insurance, which refers to the impact of the regulation on financial products, mainly the rules laid down by MiFID Regulation also to the insurance sector. $^{44}$

Although based on MiFID II, the application of the set of rules on POG needs to take into account the peculiarities of both non-life insurance and life insurance other than insurance-based investment products (IBIPs). While scenario analysis is required for IBIPs, it is reasonable that other insurance products will be tested mainly with qualitative methods rather than quantitative methods. The tests aim to assess whether the product will continue to respond, throughout its life, to the needs, characteristics and objectives of the target market identified. Qualitative methods in the form of a checklist must verify the adherence between predetermined lens (insurance needs and target) and product. They are also useful for verifying that all product-manufacturing steps have been respected. Quantitative methods, i.e. numerical analyses, should be mandatory for IBIPs and useful in support of quality tests and whenever they can confirm the correct manufacturing of the product that is being offered to the customer. POG does not list these methods. Thus, manufacturers have broad discretion in identifying and applying these methods taking into account the principle of proportionality. However, it is reasonable to expect that many manufacturers will follow particular methods with respect to specific products, while other methods will be taken as a reference for other products. This tendency towards uniform behaviour could be strengthened by the supervisory practices of the national authorities. EIOPA could then push towards convergent supervisory practices by selecting those methods that will be deemed more suitable for the objectives pursued by the POG rules, in compliance with the principle of proportionality. Hence, the manufacturing could be "standardised" across the EU not only for the process but also for products.

\footnotetext{
${ }^{44}$ Marano (2017b), p. 219 ff.; Marano (2017c), p. 415 ff. The current "Mifidization" concerns: (i) the sources of the regulation on insurance; (ii) the design and distribution of the insurance products; and (iii) customers' protection; while a potential field concerns the interpretation by the Courts.
} 
The set of rules on POG aligned the Single Market on insurance to the Insurance Core Principles (ICPs) issued by the International Association of Insurance Supervisors (IAIS). The ICPs adopted on 1 October 2011 laid down provisions on product development that have been a point of reference for the EU legislator. These provisions were updated in the version released by IAIS in November 2017. The last version is affected by the adoption of the set of rules on POG in the IDD. In particular, ICP n. 19 refers to business conduct rules of either insurers or insurance intermediaries, and standard 19.5 states that the supervisor requires insurers to take into account the interests of different types of customers when developing and marketing insurance products. Concerning jurisdictions banning the power of approval from supervisors such as the EU, guidance 19.5.5 requests supervisors to issue guidance in terms of what is expected of insurers in this regard. The contents of the guidance are listed in guidance 19.5.5, and they mirror those set by EU law. ${ }^{45}$ This identity is an outcome of the mutual influence between the EU regulation on insurance and the transnational regulation in the same field that is emerging after the global financial crisis. ${ }^{46}$

\footnotetext{
${ }^{45}$ This guidance may include the following: (i) development of products and distribution strategies should include the use of adequate information to assess the needs of different consumer groups; (ii) product development (including a product originating from a third party) should provide for a thorough assessment of the main characteristics of a new product and of the related disclosure documents by every appropriate department of the insurer; (iii) bringing a product or service to the market, the insurer should carry out a diligent review and testing of the product in relation to its business model, the applicable laws and regulations and its risk management approach. In particular, the policies, procedures and controls put into place should enable the insurer to:

- offer a product that delivers the reasonably expected benefits;

- target the consumers for whose needs the product is likely to be appropriate, while preventing, or limiting, access by consumers for whom the product is likely to be inappropriate;

- ensure that distribution methods are appropriate for the product, particularly in light of the legislation in force and whether or not advice should be provided;

- assess the risks resulting from the product by considering, among other things, changes associated with the environment or stemming from the insurer's policies that could harm customers; and

- monitor a product after its launch to ensure it still meets the needs of target customers, assess the performance of the various methods of distribution used with respect to sound commercial practices and, if necessary, take the necessary remedial action.
}

(iv) insurers should provide relevant information to intermediaries to ensure that they understand the target market (and thus reduce the risk of mis-selling), such as information related to the target market itself, as well as the characteristics of the product; $(v)$ the intermediary should, in return, provide information to the insurer on the types of customers to whom the product is sold and whether the product meets the needs of that target market, in order to enable the insurer to assess whether its target market is appropriate and to revise its distribution strategy for the product, or the product itself, when needed.

${ }^{46}$ See Marano (2017a), p. 7. 


\subsection{The Potential Effects}

The contribution of POG in building the Single Market in the insurance sector could be found in other less obvious forms.

The set of rules on POG extends the list of those affecting the organisation of the undertakings. IDD filled a gap of Solvency II in this respect. The latest Directive introduced improved governance and risk management requirements being aware that some risks may only be properly addressed through governance requirements rather than through the quantitative requirements reflected in the Solvency Capital Requirements. ${ }^{47}$ Solvency II regulated general governance requirements, fit and proper requirements, risk management, internal control, outsourcing and prudent person principle. ${ }^{48}$ Although customer protection was the cornerstone of the new regulation, a set of rules specifically addressed to the manufacture and distribution of products was missing in Solvency II. The organisational rules of POG finalise the principle of sound and prudent management to satisfy the interests and needs of the policyholders rather than to pursue the mere solvency of the insurance undertaking. The value of the insurer's solvency cannot be pursued without worrying-or worse at the expense-of creating value for insurer's customers, if the protection of policyholders and beneficiaries is the main objective of supervision in the EU as stated by Solvency II.

To qualify POG as a set of organizational rules, POG applies regardless of the Member State where the undertaking is based. POG is an integral part of the organization of the manufacturer incorporated in a specific Member State ("home country"). Thus, the home country authority must monitor compliance with POG even when the products are designed in that country and distributed in another Member State ("host country"). This supervision, however, refers to the activities of the manufacturer while those of the distributors are carried out by entities incorporated and operating under the law of the host country. As an organizational rule, POG should allow the home country authority to supervise what the manufacturer intends to distribute in the host country, but it is somewhat uncertain whether POG also allows supervision on how the products are distributed in the host country.

With this respect, POG can be described as a "circular process", where manufacturing cannot be separated from distribution, and vice versa, for the whole life cycle of the products. Monitoring of distribution, reviewing of the products and execution of remedial actions are all steps that postulate an information flow between distributors and manufacturers, which is subsequent to the marketing of the product. Products like the IBIPs have contents similar if not identical. Thus, these products may not vary considerably, when offered by a cross-border group between its subsidiaries/branches across Europe, at least in those national markets where potential customers have similar characteristics.

\footnotetext{
${ }^{47}$ See Recital 29 that adds: "An effective system of governance is therefore essential for the adequate management of the insurance undertaking and for the regulatory system".

${ }^{48}$ Siri (2017), p. $155 \mathrm{ff}$.
} 
However, in the case of cross-border activities, each of the authorities involvedhome and host - could have only a partial view of that circular process or get it late, because involving entities based in different countries. A proposal to fill this gap has already been formulated. ${ }^{49}$ It consists in extending the supervision of colleges between authorities to the POG, when the affiliation to the group can influence the insurance distribution of subsidiaries and branches. In addition to the arguments supporting that proposal, the recent Regulation (EU) 2019/1238 of 20 June 2019 on a pan-European Personal Pension Product (PEPP) provides POG requirements almost identical to those of IDD. ${ }^{50}$ Furthermore, it sets forth that the competent authorities and EIOPA shall exchange all information and documentation necessary to carry out their respective duties under such Regulation in accordance with Regulation (EU) No 1094/2010 establishing EIOPA, in particular to identify and remedy infringements of Regulation 2019/1238. ${ }^{51}$ These infringements may also concern the rules on POG. Thus, the rules on the tasks and functioning of the college of supervisors and, more general, the exchange of information between authorities should be interpreted in favour of including the information related to POG, if not to push for the introduction of specific rules in this regard.

In addition to pushing for the adoption of rules governing when manufacturing and distribution take place in different Member States, the set of rules on POG can support a convergent interpretation of the EU regulation on insurance.

The UK experience revealed that POG was built around exiting principles, and the one permeating both organizational and conduct is the following: A firm must conduct its business with due skill, care and diligence. IDD sets forth the general principle under which insurance distributors always act honestly, fairly and professionally in accordance with the best interests of their customers. Although the wording of the two principles is different, the substantial similarities between the two seem obvious. The general principle introduced by IDD, which has been mostly implemented in the Member States by simply transcribing the wording into national laws, it is likely to have twofold relevance.

A first possible relevance concerns the individual contractual relationships between distributors and customers. That is, the ability to be taken as a reference by the judges in evaluating the distributor's conduct in the presentation, conclusion and execution of a specific insurance contract. However, this principle must be coordinated with those of good faith, fairness and diligence that have long been present in the private law of the Member States. Probably, two strands of interpretation will go against each other. A tendency will be to consider the general principle introduced by IDD as a mere repetition of the general principles of private law. As a result, the principle will be substantially irrelevant to the courts. Another trend is instead to believe that this general principle is different from those already provided by private laws. Such principle regulates the specific sub-legal system of the

\footnotetext{
${ }^{49}$ Marano and Siri (2018), p. $607 \mathrm{ff}$.

${ }^{50}$ See Article 25 of Regulation (EU) 2019/1238 of 20 June 2019.

${ }^{51}$ See Article 66(4) of Regulation (EU) 2019/1238 of 20 June 2019.
} 
financial services since this rule is identical both in IDD and MiFID II. Should the latter tendency become established, the set of rules on POG would contribute to giving content to the principle in question. POG requires manufacturers to demonstrate that the product has been designed with customer interest in mind. The assessment of how the different steps of designing, monitoring and review activities have been carried out by manufacturer/distributor, could affect the decision of any dispute between manufacturer/distributor and the policyholder, at least in the event of national laws and judges allow to acquire such documentation even in judgement between the persons above. ${ }^{52}$ This eventuality would have the advantage of facilitating the distinction between the case where the failure to achieve the best interests of that client may be attributed only to the distributor or depends on the characteristics of the product designed by the manufacturer.

Other potential relevance concerns the cooperation between supervisory authorities. This field seems more promising than the previous one in achieving a common Union supervisory culture and consistent supervisory practices. ${ }^{53}$ Such cooperation is outside the private law and, therefore, it is less exposed to the conditioning of consolidated legal notions. The introduction of a general principle by European law allows these authorities to use common concepts that are detached from national principles and interpretations when they interact with each other and with EIOPA. Such a general principle also enables the authorities to fill it with detailed rules resulting from the relationship between EIOPA and national authorities. Moreover, the affirmation of a "common language" between authorities is likely to influence the individual contractual relationships, should the tendency to conceive the general principle as distinct from those already offered by private law prevail.

In general, a common understanding of the same legal rules by the authorities is a prerequisite for a common supervisory culture to be developed among them. The European System of Financial Supervision (ESFS) includes EIOPA and the competent or supervisory authorities on insurance in the Member States. The ESFS has been designed to overcome several deficiencies that emerged from the financial and economic crisis. ${ }^{54}$ The main objective of the ESFS is to ensure that the rules applicable to the financial sector are adequately implemented to preserve financial stability and to ensure confidence in the financial system as a whole and sufficient protection for the customers of financial services. Thus EIOPA has been empowered of tasks and powers including to contribute to the consistent application of legally

\footnotetext{
${ }^{52}$ Marano (2019), p. 93.

${ }^{53}$ This is a goal that supervisory authorities must pursue: see Article 29 of Regulation (EU) No 1094/2010 of 24 November 2010 establishing EIOPA.

${ }^{54}$ See Recital No. 7 of Regulation (EU) No 1094/2010 of 24 November 2010, which lists: (i) no mechanism to ensure that national supervisors arrive at the best possible supervisory decisions for cross-border financial institutions; (ii) insufficient cooperation and information exchange between national supervisors; (iii) joint action by national authorities possible only as a result of complicated arrangements to take account of the patch work of regulatory and supervisory requirements; $(\mathrm{iv})$ national solutions that are most often the only feasible option in responding to problems at the level of the Union; $(v)$ different interpretations of the same legal text exist.
} 
binding EU acts, in particular by contributing to a common supervisory culture, ensuring consistent, efficient and effective application of Solvency II and IDD. ${ }^{55}$ In both cases, these rules are addressed to national authorities to strengthen a convergent application or interpretation of the EU law on insurance.

A convergent understanding of the set of rules on POG between authorities would reduce the legal uncertainty for supervised entities and facilitates the cross-border activities. Moreover, this convergence would support authorities in complying with challenges to the supervisory approach arising from POG. Also both Regulation (EU) No 1286/2014 on PRIIPs ${ }^{56}$ and PEPP Regulation ${ }^{57}$ attribute market monitoring duties and product intervention powers to the EIOPA and national supervisory authorities, and requests national authorities to cooperate and, without undue delay, provide each other with such information as is relevant for carrying out their duties under those Regulations and of making use of their powers. If the information in the KID does not reflect the characteristics of the product offered, the supervisory authority should exercise its power of intervention. ${ }^{58}$ One of the conditions justifying the intervention of EIOPA is that national competent authority/authorities have not taken action to address the threat or the actions. ${ }^{59} \mathrm{~A}$ common supervisory culture in which the rules on POG are uniformly understood and applied would make this replacement intervention merely hypothetical. This culture is positive for customer protection, which would be timelier, but this is also good for the same supervisors. Omission or delay in their intervention may well give rise to a liability to policyholders. ${ }^{60}$

Finally, POG aims at preventing customer detriment and, therefore, requires a risk-based and prospective approach to both manufacturers and supervisory authorities. This approach is also required in the case of cross-border business. ${ }^{61}$ The organisational nature of the POG rules requires the authority of the home Member State to carry out the monitoring of the POG rules even if the products are distributed in another Member State. Manufacturers that intend to carry out the activity under the FOE regime have to provide the supervisory authority of the home Member State with information on the scheme of operations and the structure of the branch. ${ }^{62}$ This

\footnotetext{
${ }^{55}$ EIOPA has the power to issue both guidelines under the "comply or explain" procedure, and non-binding opinions. See Marano (2017a), p. $13 \mathrm{f}$.

${ }^{56}$ See Articles 15, 16 and 17.

${ }^{57}$ See Article 63.

${ }^{58}$ See Article 24(1) of Regulation (EU) No 1286/2014 as referred to information required under Articles 8(3) and 10(1).

${ }^{59}$ See Article 16(2)(c) of Regulation (EU) No 1286/2014 and Article 65(3)(c) of Regulation (EU) 2019/1238.

${ }^{60}$ See Marano (2019), p. 93 f.

${ }^{61}$ Nevertheless, Van Hulle (2019), p. 22 f. outlines that supervision on cross-border business does not always work well in practice. Home Member States might not pay as much attention to business operations concluded by their (re)insurance undertakings in the host Member State as they do to business operations concluded by these undertakings on the domestic market.

${ }^{62}$ See Article 145(2)(b) of Solvency II.
} 
information should also highlight how the set of rules on the POG is applied to products distributed in the host Member State. Otherwise, the authorization would incorporate potential damage for customers of the host Member State, for example, in the case manufacturer does not adopt any organisational supervision to ensure the products to be distributed taking into account the needs of the customers in the host country.

Although the scheme of operations does not need to be not provided in the case of activity carried out under the FOS regime, the related authorization procedure of the home country should be consistent with the aim of POG. The risk-based and forward-looking approach cannot make any distinction depending on the crossborder regimes. If the stakeholders have to wait until the authority of the host Member State establishes that a manufacturer pursuing business under the FOS regime in its territory is not complying with the legal provisions applicable to it in that Member State, ${ }^{63}$ damage to customers has already occurred while the supervisory authorities may be held liable in addition to manufacturers. Above all, certainly, the Single Market would still be a goal rather than a reality.

\section{References}

Brandt P (2011) Product distribution round-up. Compliance Off Bull

Busch D (2017) Product Governance und produktintervention unter miFid ii/miFir. J Econ Bank Law 9:409-420

Coglianese C, Mendelson E (2012) Meta - regulation and self - regulation. In: Baldwin R, Cave M, Lodge M (eds) The Oxford handbook of regulation. Oxford University Press, Oxford

Colaert V (2019) Product intervention: a cross-sectoral analysis. In: Colaert V, Busch D, Incalza T (eds) European financial regulation. Levelling the cross-sectoral playing field. Hart

Ferran E (2012) Regulatory lessons from the payment protection insurance mis-selling scandal in the UK. Eur Bus Org Law Rev 13:247

Georgosouli A (2011) The FSA's 'Treating Customers Fairly' (TCF) initiative: what is so good about it and why it may not work. J Law Soc 38(3):405-427

Gunningham N (2012) Enforcement and compliance strategies. In: Baldwin R, Cave M, Lodge M (eds) The Oxford handbook of regulation. Oxford University Press, Oxford

Marano P (2017a) Sources and tools of the insurance regulation. In: Marano P, Siri M (eds) Insurance regulation in the European Union. Solvency II and beyond. Springer

Marano P (2017b) The "Mifidization": the sunset of life insurance in the EU regulation on insurance? In: Liber Amicorum in Honour of Joannis Rokas. NOMIKH ?]

Marano P (2017c) La "Mifidización”: El atardecer de los Seguros de vida en la normativa europea sobre seguros? Revista Española de Seguros

Marano P (2019) The product oversight and governance: standards and liabilities. In: Marano P, Rokas I (eds) Distribution of insurance-based investment products. Springer

Marano P, Siri M (2018) Cross-border insurance groups: towards a comprehensive supervision under solvency II. Geneva Pap Risk Insur Issues Pract 43(4)

Marcacci A (2017) European regulatory private law going global? The case of product governance. Eur Bus Org Law Rev 18:305-332

\footnotetext{
${ }^{63}$ See Article $155(1)$ of Solvency II.
} 
Moloney N (2012) The legacy effects of the financial crisis on regulatory design in the EU. In: Ferran E, Moloney N, Hill JC, Coffee Jr JC (eds) The regulatory aftermath of the global financial crisis. Cambridge University Press, Cambridge

Siri M (2017) Corporate governance of insurance firms after solvency II. In: Marano P, Siri M (eds) Insurance regulation in the European Union. Solvency II and beyond. Springer

Tomic K (2018) Product intervention of supervisory authorities in financial services. In: Grima S, Marano P (eds) Governance and regulations. Contemporary issues. Emerald

Van Hulle K (2019) Solvency II requirements for EU insurers. Solvency II is good for you. Intersentia

\section{Legislation}

Commission Delegated Regulation (EU) 2017/2358 of 21 September 2017 supplementing Directive (EU) 2016/97 of the European Parliament and of the Council with regard to product oversight and governance requirements for insurance undertakings and insurance distributors. https://eur-lex.europa.eu/legal-content/EN/TXT/?uri=CELEX\%3A32017R2358

Directive 2002/92/EC of the European Parliament and of the Council of 9 December 2002 on insurance mediation. https://eur-lex.europa.eu/legal-content/EN/TXT/?uri=CELEX\% 3A32002L0092

Directive (EU) 2016/97 of the European Parliament and of the Council of 20 January 2016 on insurance distribution (recast). http://data.europa.eu/eli/dir/2016/97/oj

Directive 2014/65/EU of the European Parliament and of the Council of 15 May 2014 on markets in financial instruments and amending Directive 2002/92/EC and Directive 2011/61/EU. http:// data.europa.eu/eli/dir/2014/65/oj

Directive 2009/138/EC of the European Parliament and of the Council of 25 November 2009 on the taking-up and pursuit of the business of Insurance and Reinsurance (Solvency II). http://data. europa.eu/eli/dir/2009/138/oj

Regulation (EU) No 1094/2010 of the European Parliament and of the Council of 24 November 2010 establishing a European Supervisory Authority (European Insurance and Occupational Pensions Authority), amending Decision No 716/2009/EC and repealing Commission Decision 2009/79/EC. https://eur-lex.europa.eu/legal-content/EN/TXT/?uri=CELEX\%3A32010R1094

Regulation (EU) No 1286/2014 of the European Parliament and of the Council of 26 November 2014 on key information documents for packaged retail and insurance-based investment products (PRIIPs). http://data.europa.eu/eli/reg/2014/1286/oj

Regulation (EU) 2019/1238 of the European Parliament and of the Council of 20 June 2019 on a pan-European Personal Pension Product (PEPP). https://eur-lex.europa.eu/legal-content/EN/ TXT/?uri=uriserv:OJ.L_.2019.198.01.0001.01.ENG

\section{Documents}

Autorité des Marchés Financiers (AMF), La commercialisation des instruments financiers complexes, Position No 2010 - 05, of 15 October 2010. https://www.amf-france.org/en/node/59585

CONSOB, Resolution n. 9019104 of 2 March 2009 on illiquid investment products http://www. consob.it/documents/46180/46181/c9019104.pdf/64f86e70-2bb0-460a-8f60-3dd079b6341d

EIOPA, Final Report on Consultation Paper n. 16/006 on Technical Advice on possible delegated acts concerning the Insurance Distribution Directive, February 2017., https:/eiopa.europa.eu/ Publications/Reports/EIOPA\%20Final_Report_on_IDD_Technical\%20Advice.pdf 
EIOPA, Preparatory Guidelines on product oversight and governance arrangements by insurance undertakings and insurance distributors, March 2016. https://www.eiopa.europa.eu/content/ preparatory-guidelines-product-oversight-and-governance-arrangements-insurance-undertak ings_en

ESAs, Joint Position of the European Supervisory Authorities on Manufacturers' Product Oversight \& Governance Processes., https://www.eba.europa.eu/documents/10180/15736/JC-2013-77+\% 28POG+-+Joint+Position\%29.pdf

ESMA, Structured retail products - Good practices for product governance arrangements, March 2014., https://www.esma.europa.eu/sites/default/files/library/2015/11/2014-332_esma_opin ion_u_structured_retail_products_-_good_practices_for_product_governance_arrangements. pdf.

FCA, Structured Products: Thematic Review of Product Development and Governance, March 2015., https://www.fca.org.uk/publications/thematic-reviews/tr15-2-structured-products-the matic-review-product-development-and

FSA Handbook related to "The Responsibilities of Providers and Distributors for the Fair Treatment of Customers"., https://www.handbook.fca.org.uk/handbook/document/rppd/RPPD_Full_ 20180103.pdf

FSA, Treating Customers Fairly. Towards Fair Outcomes for Consumers, July 2006.; https://www. fca.org.uk/publication/archive/fsa-tcf-towards.pdf

FSA, Treating Customers Fairly. Structured Investment Products, October 2009., https:// webarchive.nationalarchives.gov.uk/20130411080807/http://www.fsa.gov.uk/pubs/other/tcf_ structured.pdf

FSA, Discussion Paper on Product Intervention, January 2011., https://www.fca.org.uk/publica tion/discussion/dp11_01.pdf

FSA, Finalised Guidance - Retail Product Development and Governance, March 2012. https:// www.fca.org.uk/publication/finalised-guidance/fg12-09.pdf

HM Treasury, A New Approach to Financial Regulation: Judgement, Focus and Stability, 2012. https://www.gov.uk/government/consultations/a-new-approach-to-financial-regulation-judge ment-focus-and-stability

IAIS, Insurance Core Principles., https://www.iaisweb.org/page/supervisory-material/icp-on-linetool

Open Access This chapter is licensed under the terms of the Creative Commons Attribution 4.0 International License (http://creativecommons.org/licenses/by/4.0/), which permits use, sharing, adaptation, distribution and reproduction in any medium or format, as long as you give appropriate credit to the original author(s) and the source, provide a link to the Creative Commons licence and indicate if changes were made.

The images or other third party material in this chapter are included in the chapter's Creative Commons licence, unless indicated otherwise in a credit line to the material. If material is not included in the chapter's Creative Commons licence and your intended use is not permitted by statutory regulation or exceeds the permitted use, you will need to obtain permission directly from the copyright holder.

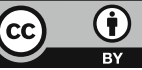

